\title{
NON-MIMETIC KNOWLEDGE AND INNOVATION PERFORMANCE: EMPIRICAL EVIDENCE FROM DEVELOPING COUNTRIES
}

\author{
TANG WANG \\ Assistant Professor in Strategy and Entrepreneurship \\ Department of Management \\ College of Business Administration \\ University of Central Florida \\ Office \#341, Building BA1, 12744 Pegasus Drive \\ Orlando, FL 32826 \\ Phone: (407) 823-5685 \\ Email: tang.wang@ucf.edu
}

DIRK LIBAERS

Associate Professor in Entrepreneurship and Innovation

Entrepreneurship \& Innovation Group

D'Amore-McKim School of Business

Northeastern University

360 Huntington Avenue, Boston, MA 02115

Phone: (617) 373-6218

Email: d.libaers@neu.edu

Keywords: Entrepreneurship/SMEs, Global/international, Open innovation

Running head: Non-mimetic Knowledge and Innovation Performance

Corresponding author: Tang Wang, University of Central Florida, tang.wang@ucf.edu 


\section{Author's Bio:}

Tang Wang: Dr. Tang Wang is an assistant professor of management in the College of Business Administration, University of Central Florida. His research focuses on two primary areas technological innovation and entrepreneurship, and top management team decision-making and governance. His work has appeared in Journal of Management, Journal of Business Venturing, Journal of Product Innovation Management and other journals.

Dirk Libaers: Dr. Dirk Libaers is an Associate Professor of Entrepreneurship \& Innovation at the D’Amore-McKim School of Business, Northeastern University in Boston, MA. He also holds visiting positions at the University of Kent in the UK and the University of Queensland in Brisbane, Australia. His research focuses on academic entrepreneurship, technology entrepreneurship, and innovation management in large, small and new companies. His work has been published in Research Policy, Journal of Business Venturing, Journal of Product Innovation Management and other journals. 


\title{
NON-MIMETIC KNOWLEDGE AND INNOVATIVE PERFORMANCE: EMPIRICAL EVIDENCE FROM DEVELOPING COUNTRIES
}

\begin{abstract}
The knowledge-based view suggests that the innovative performance of a firm is a function of the utilization and recombination of internal and external knowledge. The process of knowledge utilization and recombination to create new products can occur internally, through R\&D activities as well as externally, by making investments in creating links with suppliers, universities, customers and a wide range of actors in the innovation system. This study focuses on the impact of unique, non-mimetic external knowledge which is defined as unique technological knowledge that is not tapped by other firms in the new venture's operating environment, on the new venture's innovative performance. The purpose of the research is to investigate whether firms really benefit from utilizing and recombining unique, non-mimetic knowledge in creating innovative products in a developing country context? Drawing on the knowledge-based view and institutional theory, this study argues that entrepreneurs in their utilization and recombination of unique, non-mimetic knowledge, are not always successful at creating new products. The empirical context is drawn from the Enterprise Survey produced by the Investment Climate Group of the World Bank. The findings based on large sample of new ventures in developing countries reveals a curvilinear relationship with marginal diminishing returns between the degree of unique, non-mimetic knowledge and innovative performance. The results also show significant moderating effects of strategic product planning and economic and regulatory policy uncertainty. Specifically, strategic product planning helps in converting very unique, non-mimetic knowledge into new products. In addition, policy uncertainty can also positively moderate the process of recombining and converting unique, non-mimetic knowledge into new products. This study provides a more complete account of how unique, non-mimetic external knowledge affects innovative performance of new ventures in developing countries.
\end{abstract}

\section{Practitioner Points}

- Integrating more unique and non-mimetic knowledge is beneficial for innovation in developing countries, but the benefits decline when the knowledge becomes excessively unique and non-mimetic.

- Strategic planning is useful in mitigating the negative impact of recombining and converting highly unique, non-mimetic knowledge into new products.

- The heightened economic and regulatory policy uncertainty is beneficial to innovative performance not only when utilizing highly unique, non-mimetic knowledge (the result of distant search) but also when utilizing slightly more familiar knowledge.

\section{INTRODUCTION}

A key proposition of the knowledge-based view (KBV) is that new ventures are proficient through internal search activities - in rapidly combining existing knowledge in order to create 
new knowledge that may provide them with a competitive advantage (Conner and Prahalad, 1996; Grant, 1996). The combinative advantages of new ventures are particularly useful for developing inventions (Kapoor and Adner, 2012; Macher and Boerner, 2012). That said, there are limits to new ventures' abilities to create valuable knowledge by recombining internal knowledge, especially in the context of developing countries. These limits can be attributed in part to low levels of education among employees and the scarcity of individuals with technical skills (Zahra and George, 2002), too much reuse of existing knowledge (Ahuja and Lampert, 2001; Audia and Goncalo, 2007; Phene et al., 2006; Rosenkopf and Nerkar, 2001), and the shortage of funding for knowledge creating activities (Beck et al., 2008).

To counter these limitations, new ventures - particularly those operating in developing countries - might enrich their combinative capabilities by searching, acquiring and utilizing external technological knowledge that they lack by making investments in ties with suppliers, customers, universities, and non-profit organizations (West and Bogers, 2013). External knowledge acquisition enables new ventures to blend internal and external knowledge which has been shown to result in superior levels of innovation (Cassiman and Veugelers, 2006; Tranekjer and Knudsen, 2012). Prior research suggests that new ventures can optimize their combinative capabilities and the resulting innovative performance by integrating external knowledge that overlaps with the new venture's knowledge base yet is partially distinct from what the venture already knows (Nooteboom et al., 2007; Vasudeva and Anand, 2011). This study focuses on the impact of unique, non-mimetic external knowledge which is defined as unfamiliar technological knowledge that is not tapped by other firms in the new venture's operating environment. Unique, non-mimetic knowledge is different from the more mundane, familiar knowledge that ventures encounter in their local searches for new knowledge (Rosenkopf and Nerkar, 2001) and that is 
commonly used by other firms as well. This leads us to the first research question: To what extent does the use of unique, non-mimetic external knowledge affect the innovative performance of new ventures operating in a developing country?

Furthermore, the process of utilizing unique, non-mimetic external knowledge and converting it into new products does not occur in a vacuum and is influenced by institutions that either weaken or strengthen the social legitimacy of new ventures, their utilization of external knowledge, and ultimately their innovative activities. Institutional theory argues that formal and informal 'rules of the game' shape economic and innovative behavior and outcomes among economic actors in a country (North, 1990). One important informal institution that typically enhances the social legitimacy of ventures utilizing unique, non-mimetic external knowledge to transform it into new innovations is that of strategic product planning. Strategic product planning is an institutional practice that has been adopted widely in developed countries and is now gradually diffusing in developing countries (Calantone et al., 2003; Kostova and Roth, 2002; Song et al., 2011). A second important formal institution in developing countries is the macro-economic and regulatory policy. The current study is concerned with the uncertainty generated by macro-economic and regulatory policies (Marcus, 1981). The lack, abrupt change or inconsistent formulation and implementation of such policies would likely increase the uncertainty affecting the process whereby the utilization and recombination of unique, nonmimetic knowledge is converted into innovative new products. This leads us to the second research question in this study: to what extent does strategic product planning and the uncertainty generated by macro-economic and regulatory policies moderate the relationship between the use of unique, non-mimetic knowledge and innovative performance in a developing country? 
Our work builds and expands upon prior studies that examined search behavior by firms for the purpose of acquiring external knowledge to strengthen the recombination abilities of firms and produce significant innovations (Cheng and Huizingh, 2014; Katila, 2002; Katila and Ahuja, 2002; Laursen, 2012; Laursen and Salter, 2006; Li et al, 2013). However, none of these studies adopt a cross-country perspective and all of them use developed countries as their empirical setting. In addition, the moderating effect of institutional enablers and/or inhibitors (i.e., helping or impeding new ventures to gain social legitimacy in their utilization and recombination of new, external knowledge to create new products) on innovation in developing countries have not been adequately studied. This is surprising since new ventures in developing countries face numerous unique and heterogeneously distributed institutional obstacles not often encountered by ventures in more developed country environments (Khavul and Bruton, 2013), which makes the study of the moderating impact of institutional variables particularly salient. Therefore, it is not clear in what institutional context new ventures can take advantage, if at all, of unique, non-mimetic knowledge to enhance their innovative activities.

This study makes several contributions to the innovation literature in general, and the KBVinspired literature in particular. First, this is the first cross-country study examining the utilization of external knowledge by new ventures in a developing country context, complementing the numerous studies conducted in developed countries (Cheng and Huizingh, 2014; Chesbrough, 2003; Jones et al., 2001; Katila, 2002; Katila and Ahuja, 2002; Laursen and Salter, 2006; Love et al., 2011). Second, unlike prior research, this study explicitly focuses on unique, non-mimetic knowledge by new ventures and the impact of this type of knowledge on innovative performance. Third, this study draws on and integrates KBV and institutional theory (Grant, 1996; North, 1990) to predict the unique moderating impact of two major institutional 
factors that affect the legitimacy of new ventures in their utilization, recombination and conversion of external knowledge into new products.

\section{THEORETICAL FRAMEWORK}

\section{External Knowledge Utilization and Innovative Performance}

The KBV maintains that firms have an extraordinary capability to effectively and efficiently recombine existing knowledge for the purpose of creating new knowledge that can be embedded in new products that provide the firm with a competitive advantage (Grant, 1996; Kogut and Zander, 1992). The recombinative capability of firms enhances the firm's inventive activities and the new knowledge produced has value if it improves a firm's ability to solve techno-economic problems (Ahuja and Lampert, 2001; Rosenkopf and Nerkar, 2001).

Fleming (2001) demonstrated that valuable inventions combine diverse solution concepts or knowledge fragments with which the engineers are deeply familiar. In other words, there is evidence that firms require a variety of knowledge from different domains to create new knowledge that lead to valuable solutions that solve a particular techno-economic problem (Hargadon and Sutton, 1997). Therefore, a firm's ability to identify, access, acquire and recombine knowledge across technological domains is critical for inventive and innovative performance (Fleming and Sorenson, 2001; Hargadon and Sutton, 1997). Thus, internal knowledge variety underpins the firm's ability to recombine knowledge from across different domains and this will yield valuable inventions that may fuel innovative performance. This search for new knowledge is often referred to as local or exploitative search since it capitalizes on existing internal knowledge and skills (Jansen et al., 2006).

However, in a new venture context and particularly in developing countries, the internal knowledge variety might be low. This is due to a lack of access to well-trained researchers and 
engineers from a variety of disciplines, the initial narrow focus of a new venture's domain expertise (Padilla-Perez and Gaudin, 2014; Stinchcombe, 1965), and the well-known liabilities of newness and smallness (Freeman et al., 1983; Romanelli, 1989). Prior studies indicated that few new ventures possess all the knowledge and perform all innovative activities in-house (Baum et al., 2000; Lee et al., 2010) and R\&D investments by firms in developing countries are generally low (Padilla-Perez and Gaudin, 2014). In addition, over-use of knowledge fragments with which engineers are familiar to combine and develop new solutions result in declining benefits for the innovative character of the final solution; it leads to incremental innovations that provide only short-term benefits to the venture (Audia and Goncalo, 2007; Fleming, 2001).

For these reasons, new ventures located in developing countries may engage in distant or exploratory search for novel, unique knowledge, and particularly knowledge sources that none of its peer firms in its operating environment tap. This type of search process may result in the acquisition of external technological knowledge that augments internal knowledge variety, experimentation and the discovery of new combinations of concept solutions that yield highly valuable innovations (March, 1991; Rosenkopf and Nerkar, 2001). This type of search moves the new venture away from its current routines and knowledge bases (Katila and Ahuja, 2002) and exposes the new venture to new knowledge areas. Especially, when this unique knowledge is not utilized by a venture's peer firms, the integration and recombination of non-mimetic knowledge could result in a significant competitive advantage, because it may lead to products that enable customers to perform tasks they could not do before or in a far more efficient or effective fashion (Grant, 1996). 


\section{Baseline Hypothesis}

This study makes the assumption that new ventures in developing countries have low levels of internal knowledge diversity since they likely invent in a limited number of technology domains, although they may have some depth of knowledge in these domains. This can be attributed to the liabilities of smallness and newness and due to the fact that acquiring well trained technical personnel with a diversity of skills in developing countries is very challenging (Lundvall, 2010; Romanelli, 1989; Stinchcombe, 1965). Thus a primary constraint on their combinative abilities and innovative performance is the small number of technology domains from which novel solutions can be drawn. Low levels of internal knowledge diversity imply that new ventures are forced to search locally and improve their technologies along the existing technological trajectory, that is, incrementally (Audia and Goncalo, 2007).

The KBV suggests that significant innovations originate from the identification of nontraditional sources of knowledge and the subsequent recombination of this knowledge with existing knowledge sets (Grant, 1991; Nickerson and Zenger, 2004). The more innovative products therefore come from external knowledge sets that are not commonly tapped by other firms, i.e. unique, non-mimetic knowledge (Fleming, 2001). However, this research argues that the benefits from utilizing external knowledge that is increasingly unique and non-mimetic are non-monotonic, but rather exhibit decreasing returns.

Initially, ventures utilizing external knowledge that is still relatively familiar and occasionally used by other firms, i.e. not so unique, non-mimetic external knowledge, can enhance the recombination potential of new ventures in developing countries from this type of knowledge, and thus their innovation potential. The external knowledge starts to provide opportunities to reframe and slowly re-direct the path-dependent searches it could have pursued internally 
(Kanter, 1988). By utilizing increasingly unique and non-mimetic external knowledge new ventures would further expand the pool of cross-technology domain recombination opportunities, which could further improve the ventures' innovative performance (Phene et al., 2006; Rosenkopf and Nerkar, 2001; Smith et al., 2005). This is consistent with the literature on technological distance between knowledge bases which argues that increasing technological distance fosters new connections and links between knowledge components that enhances recombination potential within the venture (Nooteboom, 2000). In sum, according to the knowledge-based perspective, utilizing external knowledge that is more unique and non-mimetic in nature and combining that with internal knowledge should yield more innovative products. The KBV would predict a linear relationship between the utilization of unique, non-mimetic knowledge and innovative performance.

However, there may be diminishing returns to this relationship due to several knowledgebased mechanisms that counter the increasingly positive impact of unique, non-mimetic knowledge on innovative performance. More specifically, ventures that tap knowledge sources or search targets that hold knowledge that becomes too different, i.e. unfamiliar and not used by peer firms (i.e. highly unique, non-mimetic knowledge) may start to hurt the innovative performance of new ventures. This phenomenon can be explained as follows. First, increasing levels of uniqueness and unfamiliarity of the external knowledge also imply that this knowledge is increasingly tacit and complex, inhibiting the smooth transfer of this knowledge across new venture boundaries (Kogut and Zander, 1992; Polanyi, 1966). Second, to recognize and acquire very unique, non-mimetic knowledge and pursue cross-technology domain recombination opportunities, engineers in new ventures must have sufficient understanding of the relevant technology domains in order to be able to recognize, assimilate, integrate and recombine this 
knowledge with internal knowledge to develop novel innovations (Cohen and Levinthal, 1990; Jeppesen and Lakhani, 2010; Nooteboom, 2000). An adequate level of cross-technology domain understanding is likely to be problematic in new ventures in developing countries because of relative low levels of R\&D investment (Intarakumnerd et al., 2002).

For these reasons, and in the spirit of the $\mathrm{KBV}$, it can be argued that there may be a level of external knowledge uniqueness and non-mimeticness that optimizes the recombinative potential of new ventures, and increase the innovative performance. Hence:

H1: The relationship between the degree of unique and non-mimetic knowledge and a new venture's innovative performance is curvilinear with marginal diminishing returns.

\section{Contingent Impact of Strategic Product Planning and Policy Uncertainty}

The process of utilizing and recombining external novel knowledge with internal knowledge to create new innovations does not occur in a vacuum and is likely affected by contextual factors. Social scientists in general and innovation scholars in particular have recognized the significant impact of institutions on innovative activity (Barbosa and Faria, 2011; North, 1990). This study draws on institutional theory to assess the moderating impact of two institutions, one informal and at the firm-level and one formal and at the country-level, on the relationship between the utilization of unique, non-mimetic external knowledge and the innovative performance of new ventures in a developing country setting. While several institutions may moderate the focal relationship examined here, institutional theory literature pertaining to innovation highlights two salient factors; strategic product planning (Oliver, 1991; Song et al., 2011) and the changes in macro-economic and regulatory policy, and the resulting policy uncertainty generated (Marcus, 1981). The first institution refers to a best practice that has become the norm in developed countries, in both new ventures and more established firms and is gradually making its way into developing countries; the degree of strategic product planning to support a new venture's 
innovation strategy (Miller and Cardinal, 1994; Song et al, 2011). A second institution refers to policy uncertainty generated by macro-economic and regulatory policies (Marcus, 1981). The share of government expenditure, the share of public investment in GDP, tax policy, intellectual property policy, domestic credit expansion or contraction and the nature and extensiveness of regulatory policies are all examples of formal institutions (Freeman and Soete, 1997). Policy uncertainties in many developing countries arise because of inconsistent formulation and implementation of their macro-economic and regulatory policies or when policies that are at the normative 'right' level do not persist over time (Rodrik, 1991). Such policy uncertainties can significantly affect the process of how unique, non-mimetic external knowledge is recombined with internal knowledge and converted into innovations and entrepreneurial-related outcomes (Aldrich and Herker, 1977; Bowen and De Clercq, 2008).

Strategic product planning. Strategic product planning is a well-established institutional practice in both established and new firms in developed countries that is argued to support innovation strategy, firm growth and performance (Moorman and Miner, 1998). Strategic product planning is a formal, administrative process that codifies an explicit procedure to determine specific, medium-to-long range objectives with regard to product mix and target markets (Armstrong, 1982; Chwolk and Raith, 2012). The process establishes the means and ends of an organization, clarifies competitive threats and opportunities, identifies the knowledge and expertise required for future products, and specifies the controls and implementation activities to bring these future products to market (Song et al., 2011). A clear formal strategic product plan provides details and tactics that ensure successful formulation and implementation of the venture's innovation strategy going forward (Chwolk and Raith, 2012; Moorman and Miner, 1998). 
Developing new products is an unpredictable activity, especially so in developing countries where knowledge sources are both scarce, concentrated and poorly integrated at the national, regional or local level (Fagerberg and Srholec, 2008). Especially, new products developed by new ventures in developing countries (and the new ventures themselves) have to overcome a higher bar of institutional approval and social acceptance. Institutional theory predicts that by adopting a similar practice as foreign firms and large established indigenous firms in its operating environment, e.g. strategic product planning (DiMaggio and Powell, 1983; Kostova and Roth, 2002) new ventures may reduce the uncertainty influencing the process of recombining and converting unique, non-mimetic knowledge into new products. As such, the knowledge utilization process as well as the resulting new products will be viewed as more legitimate and desired by customers under more extensive strategic product planning. Adoption of strategic product planning therefore will enhance the effectiveness of new ventures' innovation process that transforms external knowledge of varying levels of uniqueness and nonmimeticness into new, legitimate products wanted by customers (DiMaggio and Powell, 1983; Kostova and Roth, 2002) relative to new ventures that do not adopt strategic product planning. Moreover, a more extensive degree of product planning by new ventures grants more legitimacy to these ventures in that it signals a clear effort to make the recombination and conversion process of unique, non-mimetic knowledge into new innovations more effective, similar to the adoption of Total Quality Management (TQM) which led to increased efficiencies in business processes and enhanced quality outcomes (Westphal et al., 1997). The beneficial impacts of TQM among larger organizations then exerted normative pressures on smaller firms (e.g. suppliers) to socially conform to the institutional practice of TQM in order to be viewed as a legitimate player in the economy. In our case, the enhanced legitimacy gained by adopting 
strategic product planning will therefore engender inter-organizational trust between the focal venture and the external knowledge sources it seeks to tap, increases absorptive capacity and facilitates the transfer of unique, tacit non-mimetic knowledge and its recombination with internal knowledge to produce new products. Moreover, the reduction in uncertainty as a result of strategic product planning affecting the innovation process will be more pronounced for external knowledge that is more unique and non-mimetic since strategic product planning provides guidance on what steps to take to recognize, acquire, assimilate, and recombine this highly unfamiliar knowledge with internal knowledge to create new products. As a result, strategic product planning will soften the impact of diminishing returns when using very unique, non-mimetic external knowledge. Therefore:

H2: Strategic product planning positively moderates the curvilinear relationship between the degree of unique, non-mimetic knowledge and innovative performance, and specifically helps in attenuating the impact of diminishing returns at high degree of unique, non-mimetic knowledge utilization.

Economic and regulatory policy uncertainty. Uncertainty regarding regulatory and macroeconomic policies is an integral part of a particular institutional context and can have a significant impact on the process that recombines and converts unique, non-mimetic knowledge into new innovations. This study proposes that the curvilinear relationship between the utilization of unique, non-mimetic knowledge and new ventures' innovative performance is positively moderated by the degree of economic and regulatory policy uncertainty. This research proposes two reasons for this moderating effect.

First, institutional theory posits that changes in the 'rules of the game' will open doors for some and close doors to other actors in the economic system (North, 1990). The institutional environment and changes in institutions that generate uncertainty, shape the structure of economic incentives, and thereby expand or limit the scope of strategic choices available to 
organizations, e.g. like developing and introducing innovations (DiMaggio and Powell, 1983; Tolbert and Zucker, 1983). For new ventures utilizing unique, non-mimetic knowledge, these changes offer an increased range and frequency of potential innovation opportunities. By virtue of their nimbleness and non-hierarchical structure- new ventures can swiftly take action to exploit these emerging opportunities (Freel, 2005). What this implies is that for every level of unique, non-mimetic knowledge utilization, the external knowledge that is obtained under uncertain environmental conditions can be recombined with internal knowledge in a unique fashion and applied to a broader set of product innovations targeted at a richer set of market opportunities. Thus, changes in customer demand, in the relative composition of industries, in the degree of economic restructuring, in currency exchange rates and in regulatory requirements can yield competitive advantages to firms converting unique, non-mimetic knowledge into new products (Calantone et al., 2003).

Second, under high levels of uncertainty, organizations tend to engage in more boundary spanning activities to avoid or at least mitigate risks. Boundary spanning activities help the information transmission and filtering between the environment and organization as well as the summarization and interpretation of the information being transmitted and filtered (Aldrich and Herker, 1977; Miles, 1980). For new ventures in developing nations, such boundary spanning activities can facilitate the recombination and conversion of external knowledge into new products in three ways: 1) reducing the risk of information overload when recombining unique and non-mimetic knowledge; 2) understanding, interpreting and inferring information from environmental shifts; and 3) selecting various aspects of unique and non-mimetic knowledge for recombination to effectively respond to these environmental shifts. Therefore, the intensification of boundary spanning activity as a response to increased policy uncertainty will enable the 
integration and recombination of unique, non-mimetic knowledge to create new products (Rosenkopf and Nerkar, 2001). In other words, heightened policy uncertainty will trigger increased boundary spanning activity that facilitates the process of acquiring, utilizing and recombining unique, non-mimetic external knowledge with internal knowledge to create new products, boosting the new venture's innovative performance. Hence:

H3: The level of economic and regulatory uncertainty positively moderates the curvilinear relationship between the degree of unique, non-mimetic knowledge and innovative performance, and specifically helps in attenuating the impact of diminishing returns at high degree of unique, non-mimetic knowledge utilization.

\section{Sample}

\section{METHODOLOGY}

To investigate the impact of the degree of unique, non-mimetic knowledge on innovative performance among new ventures across countries, this study uses recently collected firm-level data from the Enterprise Survey produced by the Investment Climate Group of the World Bank. The survey provides company-level data on both manufacturing and service firms in countries from the world's emerging markets and developing economies. The detailed list of the countries can be found in Part A of Table 1. It uses standardized survey instruments and a uniform sampling methodology to minimize measurement error and to yield data that are comparable across economies. World Bank researchers located in the various countries conducted personal interviews with prequalified firm representatives. Survey instruments were translated and backtranslated to ensure consistency (Martin et al., 2007). The survey was conducted from 2002 to 2005. Further information regarding the sampling frame, non-response bias, and other potential biases is available from the Enterprise Survey website (http://www.enterprisesurveys.org/). The sample was used in numerous previous studies (e.g. Beck et al., 2008; Martin et al., 2007). 
Two criteria are imposed to construct a sample of firms appropriate for our analysis. First, the data is restricted to ventures operating in the manufacturing sector to ensure that the concept of product innovation is consistent across the firms examined. The detailed list of all the subcategories of manufacturing sector can be found in Part B of Table 1. The questionnaire used for service firms is also more limited, and crucial information on technological capabilities is not asked. And second, the sample includes firms less than 10 years old, which enables us to examine the utilization of external knowledge for innovative activities in early-stage and new ventures (Carpenter et al., 2003; Fernhaber and Li, 2010). The reasons that this study only focuses on new ventures are as follows. First, it is reasonable to believe that the three most important external sources will be adequate to account for the rather limited attention bandwidth of entrepreneurs and because of less complex search activities undertaken by them. Second, because of the liability of newness, small and young firms often face severe resource constraints. As a result, the utilization of external knowledge for innovation can be a more urgent yet challenging issue because of the lack of absorptive capacity and limited exposure to the external environment. In other words, by focusing on those small and young firms, this study is better able to capture the tension between utilization of unique, non-mimetic knowledge and more mundane, mimetic knowledge which is hypothesized as the inverse U shape in H1. Third, the focus on small and young firms also makes the two moderating factors more theoretically relevant. Numerous studies in entrepreneurship have pointed out the significant and direct effect of business planning for new venture performance (e.g. Delmar and Shane, 2003), yet little research has paid attention to its moderating effect on the conversion of external knowledge into new products. In addition, relative to established firms, macroeconomic and regulatory 
uncertainty tends to produce even more opportunities for small and young ventures which are less bound by the internal routines and rigidity (Freel, 2005).

The imposition of this set of restrictions as well as the non-missing data results in a unique firm-level sample of 1583 entrepreneurial firms that are less than 10 years old and operate in multiple manufacturing sectors in 14 developing countries. The sample includes two of the BRICS countries, Brazil and South Africa. Also, the countries contributing most of the sample include Brazil, South Africa, Thailand, and the Philippines - all economies that are dominated by manufacturing industries. Therefore, the sample represents manufacturing activities in both developing and emerging countries. The firms are categorized in the following manufacturing industries: (1) machinery, electronics, chemical manufacturing, (2) textiles, leather, garments, (3) food and beverage, and (4) other types of manufacturing. Consistent with our criteria for selecting new firms, the firms in our sample are on average six years old. Only $5 \%$ of the firms are public, leaving the majority as privately held firms.

$$
<<\text { Insert Table } 1 \text { here }>>
$$

\section{Dependent Variable}

Innovative performance. Innovative performance is measured by the number of new products introduced by the responding firm in the past three years which is a commonly used measure for a firm's innovative outcome, particularly in manufacturing industries (Katila, 2002; Katila and Ahuja, 2002). In the robustness analysis, considering the potential distinctions between product and process innovations (Leiponen and Helfat, 2010), this research also conducts the statistical analysis on process innovations only. The survey question pertaining to process innovations is whether the firm has introduced new technology that has substantially changed the way that the 
main product is produced, which is also commonly considered as a type of innovation when studying manufacturing industries (Leiponen and Helfat, 2010).

\section{Independent Variable}

The independent variable of this study is the utilization of unique, non-mimetic knowledge by the new venture measured in the country it operates in. While prior research on the utilization of unique, non-mimetic knowledge tends to focus on the industry level, this study focuses on the country level for two reasons. First, the external knowledge sources in each of the developing countries examined here, due to the presence of weak or even a complete lack of formal institutions, exert strong informal institutional influences on firms' innovation processes. In other words, it is argued that institutional influences occur at the macro level and firms have to pay attention to what knowledge other peer firms are utilizing in their innovation processes. The literature on national innovation systems suggests that the national innovation system of a developing country is "specifically related to the country's development level. Therefore, it is important to connect the level of NIS [national innovation system] development with the level of economic structural and institutional development” (Intarakumnerd et al., 2002, p. 1447). Second, institutional forces and incentives tend to also differ across nations, depending on the resources available, government's industrial policy, and firm's awareness of external knowledge available. Moreover, this study in particular focuses only on manufacturing industries which largely teases out the cross-industry variations since firms in different industries may be subject to different types of institutional and knowledge search and utilization constraints (e.g., manufacturing vs. financial industries in developing countries), and to focus on one single group of industries, i.e. manufacturing will help to control for such differences. 
In the survey, each firm is asked to name the three most important external sources through which the firm acquired technological knowledge from 12 sources of external knowledge (e.g., embodied in new machinery or equipment, by hiring key personnel, licensing or turnkey operations from international sources, licensing or turnkey operations from domestic sources, developed or adapted within the establishment locally, transferred from parent company, developed in cooperation with client firms, developed with equipment or machinery supplier, from a business or industry association, trade fairs and/or study tours, consultants, and from universities, public institutions). That is, the survey asked the respondents to rank their most important knowledge sources, i.e. list the most important one, the second most important one, and finally the third most important one. Because this study only includes ventures aged 10 years or younger, it is reasonable to believe that the three most important external sources will be adequate to account for the rather limited attention bandwidth of entrepreneurs and because of less complex search activities undertaken by them (Fernhaber and Li, 2010; Stinchcombe, 1965).

The measure of unique, non-mimetic knowledge utilization is constructed as follows ( $i$ and $j$ refer to the company $j$ in country $i$ ):

$$
\text { nonmimetic_utilization }_{i, j}=\sum_{y=1->3} \sum_{x=1->12} \text { dum }_{-} \text {source }_{y, x, i, j} \times \text { nonmimetic_source }_{x, i} \times \text { import_source }_{y, i}
$$

In the equation above, dum_source $y_{y, x, i, j}$ are dummy variables representing whether each of the 12 sources $(\mathrm{x}=1,2, \ldots, 12)$ was selected as one of the three most important sources $(\mathrm{y}=1,2,3)$ by firm $j$ in country $i$.nonmimetic_source,$i$ measures the degree of non-overlap of the 12 different knowledge sources in the same country, and import_source s.i $_{-i}$ are the weights that measure the degree of importance of the three selected knowledge sources.

First, to measure the degree of non-overlap of the 12 different knowledge sources in the same country (nonmimetic_source ${ }_{x, i}$ ), the method first calculates the frequency of each search activity 
as a country-specific measure (i.e., how common the knowledge sources are searched among peer firms in the same country), and then use 1 minus the frequency percentage. In other words, the more frequently a certain knowledge source is tapped by peer firms in the same country, the lower the degree of non-overlap of the knowledge source is, i.e. the more mimetic the knowledge is. For example, for the country of Brazil, $15.86 \%$ of the firms report to acquire knowledge that is embodied in new machinery or equipment. Thus, the non-mimetic_source,$i$ measure for acquiring knowledge embodied in new machinery or equipment in Brazil is 0.8414 (1-15.86\%). That is, if more firms in Brazil acquire knowledge embodied in new machinery or equipment in the manufacturing industry, due to technology spillovers and learning by imitating, such knowledge source is unlikely to be unique and non-mimetic. This method has been adopted by previous studies (Boardman, 2009; Bozeman and Gaughan, 2007; Libaers and Wang. 2012).

The measure also includes the degree of importance of the three selected external sources in the equation (import_source in, $_{\text {) }}$. Li and Chi (2013) used the relative importance of each of the industries in the venture capital firm's portfolio to measure the importance of the portfolio focus. The rationale for adding the importance score of each of three most important sources is to capture the intensity of the non-mimetic search. While the nonmimetic_source measure (nonmimetic_source, i) captures the non-mimetic nature of that specific knowledge source, the measure still has to consider the intensity or reliance on that knowledge. For instance, for the country of Brazil, $15.86 \%$ of the firms report to acquire knowledge embodied in new machinery or equipment. Thus, the non-mimetic_source measure (nonmimetic_source,$i$ ) for acquiring knowledge embodied in new machinery or equipment in Brazil is $0.8414(1-15.86 \%)$. Then, for a specific company in Brazil, if it ranks the acquired knowledge embodied in new machinery or equipment as the most important source of knowledge search AND 100\% of firms in Brazil only 
search for one source (the most important source, no second source, no third source), then it means all firms rely on the single one source of knowledge, regardless of what the source is (in this case knowledge embodied in new machinery or equipment). Therefore, the score of $0.8414 * 100 \%$ is assigned. On the other hand, if it ranks the acquired knowledge embodied in new machinery or equipment as the most important source of knowledge search AND only $10 \%$ of firms in Brazil only search for one source, then it means the reliance on the most important source is low which leads to the score of $0.8414 * 10 \%$. For the country of Brazil, $97 \%$ of the firms report to acquire knowledge from source\#1, 95\% of the firms report to acquire knowledge from source\#2, and $88 \%$ of the firms report to acquire knowledge from source\#3. Thus, import_source $_{1, \text { brazil, }}$ import_source 2, brazil, and import_source 3, brazil are assigned 97\%, 95\%, and $88 \%$ respectively as the weights. To further validate the operationalization at the country level, the analysis of variance (ANOVA) is performed on the variables of nonmimetic_source , $_{, i}$. ANOVA partitions the variance between and within countries. The results based on the F test suggest that nonmimetic_source ${ }_{x, i}$ is significantly different across countries $(\mathrm{F}$ value $=25.44$, $\mathrm{p}<0.01)$. In other words, firms from different countries do engage in the utilization of knowledge with different levels of uniqueness and non-mimeticness.

\section{Moderating Variables}

Strategic product planning. This variable refers to the number of months ahead the management of the venture planned its activities with regard to product mix and target markets.

Economic and regulatory policy uncertainty. This variable is measured on a four-point scale and gauges the degree of uncertainty in the macro-economic and regulatory policy environment in the country. 


\section{Control Variables}

Because this study attempts to analyze how utilization of unique, non-mimetic external knowledge affects innovative performance, firm-level factors have to be controlled. Firm age and size. Firm age is measured by the difference between the year the firm was founded and the year the survey was conducted. Firm size is measured by the natural log of the number of employees. Prior research indicates that older firms tend to have lower product innovation probabilities. As firms grow in size, more attention is diverted away from developing novel products and towards maintaining a growing number of product lines. TMT education level is measured by the highest level of education among the top managers using six levels from secondary school to post graduate degree. TMT work experience is measured by the total number of years of TMT's experience working in the industrial sector. Both TMT demographic variables have been shown to affect product innovation rates (Smith et al., 2005). Foreign investment is a dummy variable taking the value 1 if the firm receives any foreign investment, and 0 otherwise. $R \& D$ investment is a dummy variable taking the value 1 if the firm invests in formal research and development, and 0 otherwise. Spending on R\&D affects rates of new product introduction (Artz et al., 2010). Public firm is a dummy variable taking the value 1 if the firm is public, 0 otherwise. The model also controls for Operational slack variable which is related to external knowledge search. Operational slack refers to temporal, labor, or physical excesses in production processes, and is measured as the average production capacity utilization over the last year (Chen, 2008). The question in the survey asked respondents what the establishment's average capacity utilization was over the last year.

The dependent variable is the number of new products introduced by the firm in the last three years. This is a count variable. Examination of this variable reveals that three attributes 
characterize the first dependent variable: nonnegative, small mean, and over-dispersion. As discussed by Hoffmann (2004), the distribution of a count variable with a large mean and large sample is close to a normal distribution and hence linear regression may be applied. However, the mean of this variable is very small and over-dispersion can be observed (Long, 1997). As a result, negative binomial regression analyses are more appropriate techniques for testing our hypotheses and tests for over-dispersion. Our data is clustered by country. Because of the count nature of the dependent variable, the model uses country dummy fixed effect to control for any unobservable country difference in driving innovative performance.

\section{RESULTS AND DISCUSSION}

\section{Descriptive Statistics}

The descriptive statistics are provided in Table 2, and on average, firms introduced 2 new products in the past three years, with a maximum of 15 new products. The average age of the firms is 6 years old. In particular, there is a strong correlation between country's income and the utilization of unique, non-mimetic knowledge $(\gamma=0.30, \mathrm{p}<0.01)$ which suggests that the highincome bracket countries tend to have higher levels of unique, non-mimetic knowledge utilization likely due to a richer and more diverse external knowledge availability and firm's awareness of external knowledge sources.

$$
<<\text { Insert Table } 2 \text { here }>>
$$

Table 3 presents the negative binomial regression for the dependent variable of number of new products. To mitigate the potential for multicollinearity associated with the quadratic and interaction terms, the independent and moderating variables are standardized before running the regressions. The maximum value of the variable inflation factor (VIF) is 4.97 and the maximum 
value of the conditional index $(\mathrm{CI})$ is 15.52 , which suggests that multicollinearity is not a concern. Hypothesis testing will be based on the regression results in Table 3.

$$
<<\text { Insert Table } 3 \text { here }>>
$$

The model incrementally introduces variables of interest to examine the model fit improvement and to provide a further robustness test of the results. In Model 1, the model only includes the control variables. In Model 2, the model adds the main variables, utilization of unique, non-mimetic knowledge with both linear and quadratic terms. Models 3 and 4 include the interaction terms between strategic product planning, policy uncertainty, and utilization of unique, non-mimetic knowledge respectively. Model 5 is the full model which suggests that the results are consistent with the partial models. The comparison between Models 1 and $2(2 \log$ likelihood $($ Model $2-$ Model 1) $=24.76, p<0.01)$ suggests that the inclusion of linear and squared terms make the model fit better. By including the moderating effects of strategic product planning in Model 3 and policy uncertainty in Model 4, the model fit is significantly improved over Model 2 (although the difference is not significant between Models 3 and 2, the results on the coefficients are consistent between Models 3 and 5). To clearly illustrate the moderating effects, the simulation-based graphs are created following Zelner (2009) to handle the nonlinearity of the model using the STATA command "intgph". The figures are drawn by setting the value of the independent variables other than main predictors and moderators to zero (Hoetker, 2007).

\section{Hypothesis Testing}

Hypothesis 1 predicts that the relationship between the degree of unique, non-mimetic knowledge and a new venture's innovative performance is curvilinear with marginal diminishing returns. The study adopts a similar approach pioneered by Karim (2009) and use three steps to 
further test the existence and significance of marginal diminishing returns. First, the results in Model 2 suggest that there is a significant and negative coefficient for the squared term of unique, non-mimetic knowledge utilization $(\beta=-0.20, \mathrm{p}<0.01)$. Second, the inflection point is calculated when the slope equals to zero: $\beta_{1}+2 * \beta_{2} \times \gamma=0 ; \beta_{1}=0, \beta_{2}=-0.20$. Therefore, $\gamma=0$. Because the unique, non-mimetic knowledge utilization variable has been standardized before inclusion in the regression, the inflection point of the curvilinear curve can be reached when unique, non-mimetic knowledge utilization equals the mean. Therefore, the inflection point at the mean is within the data range from 0 to 2.71 . Third, the study also tests the sign of the slope at both the left and right extreme point. The left and right extreme points correspond to -1 and 1 . For the left extreme point, $\beta_{1}+2 * \beta_{2} \times(-1)=0.40(\mathrm{p}<0.01)$. Therefore, the null hypothesis that the slope at the left extreme point equals to 0 is rejected. On the other hand, for the right extreme point, $\beta_{1}+2 * \beta_{2} \times 1=-0.40(\mathrm{p}<0.01)$. Therefore, the null hypothesis that the slope at the right extreme point equals to 0 is also rejected. Based on the comprehensive testing results above, it can be concluded that the relationship between unique, non-mimetic knowledge utilization and innovative performance is curvilinear with marginal diminishing returns, supporting Hypothesis 1.

Hypothesis 2 predicts that strategic product planning positively moderates the curvilinear relationship between the degree of unique, non-mimetic knowledge and innovative performance, and especially helps in attenuating the impact of diminishing returns when utilizing highly unique, non-mimetic knowledge. In Model 3 and Model 5, the coefficient of the interaction between utilization of unique, non-mimetic knowledge and strategic product planning is positive and significant $(\beta=0.13, \mathrm{p}<0.10$ in Model 3; $\beta=0.12, \mathrm{p}<0.10$ in Model 5). The coefficient of the interaction between the squared term of utilization of unique, non-mimetic knowledge and 
strategic product planning is not significant. Figure 1 illustrates the moderating effect of strategic product planning. The $\mathrm{x}$-axis is the standardized utilization of unique, non-mimetic variable so the 0 refers to the mean value. Figure 1 depicts the difference in expected value of new products associated with an increase in strategic product planning across knowledge of different degrees of uniqueness, and non-mimeticness, along with the $95 \%$ confidence interval for this difference. The figure indicates that, even though the estimated difference of strategic product planning on the expected value of new products is negative when utilizing rather familiar knowledge also used by peer firms, this effect is not statistically significant in this region because the $95 \%$ confidence interval includes 0 . In other words, strategic product planning appears not effective when recombining familiar and more mimetic knowledge into new products. In contrast, when utilizing very unique, non-mimetic knowledge (to the right of the mean value ), not only is the effect of strategic product planning positive in terms of difference in expected value of new products, but it is also significantly different from 0 . Therefore, when utilizing very unique, nonmimetic knowledge, more extensive product planning is more beneficial to improve innovative performance. Thus, $\mathrm{H} 2$ is partially supported for the positive moderating effect of strategic product planning.

$$
<<\text { Insert Figure } 1 \text { here }>>
$$

Hypothesis 3 predicts that the level of economic and regulatory policy uncertainty positively moderates the curvilinear relationship between the degree of unique, non-mimetic knowledge and innovative performance, and specifically helps in attenuating the impact of diminishing returns when utilizing very unique, non-mimetic knowledge. In Model 4 and Model 5, only the coefficient of the interaction between the squared term of the utilization of unique, non-mimetic knowledge variable and policy uncertainty is positive and significant $(\beta=0.16, p<0.01 ; \beta=0.15$, 
$\mathrm{p}<0.05$ in Model 5). Figure 2 illustrates the moderating effect of economic and policy uncertainty. The $\mathrm{x}$-axis is the squared term of the standardized utilization of unique, non-mimetic knowledge variable so the 0 refers to the mean value and it only has positive value. Figure 2 depicts the difference in the expected value of new products associated with an increase in policy uncertainty at different levels of unique, non-mimetic knowledge utilization, along with the 95\% confidence interval for this difference. The horizontal axis in the figure denotes the squared term of the standardized variable of the utilization of unique, non-mimetic knowledge. Therefore, the figure indicates that the estimated impact of policy uncertainty on the difference in expected value of new products is negative and significant when utilizing relatively unique, non-mimetic knowledge (between one standard deviation below and above mean). In other words, policy uncertainty appears to have a negative impact when recombining more familiar and more mimetic knowledge. In contrast, when utilizing very unique and non-mimetic knowledge, the moderating effect of policy uncertainty is positive and significant in terms of difference in expected value. Thus, $\mathrm{H} 3$ is partially supported as the positive moderating effect of policy uncertainty is found when using familiar, mimetic knowledge or when utilizing very unique, non-mimetic knowledge.

$$
<<\text { Insert Figure } 2 \text { here }>>
$$

\section{Robustness Tests}

The study splits the sample and run several robustness tests to confirm the results are shown in Table 4. The first robustness test focuses on the industry level. To perform this test, this study selects the most dominant sector in the manufacturing industry in the sample (almost $50 \%$ of the firms come from the dominant sector): Machinery, electronics, chemical manufacturing, and other materials manufacturing firms. Model 6 suggests that the results are broadly consistent 
with the findings in Model 5 with a significant and negative coefficient for the squared term of the utilization of unique, non-mimetic knowledge variable. In addition, the coefficient for the interaction term between the utilization of unique, non-mimetic knowledge variable and strategic product planning and policy uncertainty, respectively, are also positive and significant, similar to Models 3 and 4. Therefore, while the utilization of unique, non-mimetic knowledge variable is constructed at the country-level, similar findings appear to hold for the single and largest manufacturing sector across those countries. In addition, the study examines the results for the high-income countries among all the developing countries in the sample (GNI>\$1000) in Model 7 and the results are largely consistent with Model 5 as well. Such robust results imply that the way the variables are constructed at the country-level holds when focusing on the high-bracket income countries. The only exception is that the moderating effect of policy uncertainty becomes insignificant, implying that the impact of economic and policy uncertainty in higher income countries is immaterial which is consistent with our theoretical argument. Furthermore, this study incorporates Model 8 based on the two BRICS countries, Brazil and South Africa, combined and the results remain similar to the main findings in Model 5, although no impact of strategic product planning can be observed. Therefore, the results are robust across countries and the country-level unique, non-imitative knowledge utilization measure is valid.

Regarding the dependent variable, it should be acknowledged that product and process innovations may be fundamentally different. Yet, process changes or upgrades are also widely considered as an important strategy of innovation. Given the developing country context, this study therefore considers process innovation as a critical outcome of innovative activity as well. The analysis on process innovation only is reported in Model 9 and the results are also consistent with Model 5. The only exception is that the moderating effect of policy uncertainty becomes 
insignificant, implying that manufacturing firms in developing countries are largely focused on product rather than process innovation to cope with economic and policy uncertainty. Finally, observations from a few developed countries in the manufacturing sectors are included in the survey. However, for the limited number of developed countries available, the main dependent variable of new products is largely missing. Instead, this research adopts process innovation as the dependent variable and include a limited number of observations from developed countries: Germany, Greece, Ireland, Portugal, and Spain. The results are shown in Model 10 and suggest that the main findings are still valid across a limited number of developed country firms.

$<<$ Insert Table 4 here $>>$

\section{CONCLUSIONS}

\section{Discussions of the Results}

This study sought to examine how the utilization of unique, non-mimetic external knowledge affects innovative performance in a set of new ventures operating in a wide range of developing countries. Our baseline result suggests that the relationship between the utilization of unique, non-mimetic knowledge and new venture innovative performance is inverse curvilinear with diminishing returns. The results show that strategic product planning, as an institutional practice and as an uncertainty reduction device appears only useful in mitigating the negative impact of recombining and converting highly unique, non-mimetic knowledge into new products (see graph in Fig 1). In contrast, strategic product planning appears not effective when just planning for product extensions or incrementally improved products for which recombination of familiar and more mimetic knowledge suffices. Furthermore, with regard to the moderating impact of uncertainty generated by macro-economic and regulatory policy, the empirical results show again a pattern similar to that of strategic product planning in terms of the moderating effect. The 
finding suggests that heightened economic and regulatory policy uncertainty is beneficial to innovative performance not only when utilizing highly unique, non-mimetic knowledge (the result of distant search) but also when utilizing slightly more familiar, knowledge that is also used by peer firms. However, a surprising finding based on Figure 2 is that policy uncertainty also plays a modest negative moderating role when utilizing familiar knowledge that is also tapped by a venture's peers. A possible explanation for this finding may be that recombining such type of external knowledge with internal knowledge might lead to new products that are somewhat imitative, and therefore not being perceived as a truly new product by customers whose preferences are changing. But at the same time, because it is also somewhat novel to the firm, the utilization of such external knowledge may create internal chaos and resistance to change, which results in a lower innovative outcome.

\section{Theoretical Implications}

This study contributes to the entrepreneurship and innovation literature in three ways. First, this research draws on and integrates KBV and institutional theory since firms engaged in knowledge acquisition and recombination in their attempts to develop new products face both daunting challenges in terms of knowledge integration and legitimacy acceptance, especially so in a developing country context. Specifically, the downward sloping section of the curvilinear relationship in particular suggests that the utilization of highly unique, non-mimetic knowledge by tapping more independent and unique knowledge sources has negative consequences for innovative performance consistent with more recent work in the KBV tradition (Laursen, 2012; Laursen and Salter, 2006). Utilizing external knowledge from sources that are less frequently tapped by peers in the same country comes at a cost however due to a lack of absorptive capacity 
and ventures' inability to effectively integrate and synthesize that very unique and often tacit knowledge in its current knowledge base.

Second, our study extends KBV and institution theory by suggesting that planning as an uncertainty reduction device can be more effective when converting highly unfamiliar (and thus uncertain) and non-mimetic knowledge into new products. The literature based on developed countries has indicated that product planning entails the preparatory homework required to make the process of utilizing, recombining and converting knowledge into new products more effective. This study further suggests that uncertainty reducing mechanisms such as strategic product planning are most appropriate when performing distant, exploratory searches for external knowledge and the subsequent utilization of that knowledge (Aldrich and Herker, 1977). The effects are particularly pronounced in a developing country context as the results suggest. Ventures can perform more extensive product planning as effective mechanisms to alleviate legitimacy concerns (and reduce uncertainty) (DiMaggio and Powell, 1983; Kostova and Roth, 2002). Moreover, extensive strategic product planning are helpful in countering the negative impact of integrating and recombining very unique, non-mimetic knowledge on innovative performance (the section exhibiting diminishing marginal returns).

Third, our study highlights new theoretical insights of environmental uncertainty for innovations. Policy uncertainty, in this case economic and regulatory policy uncertainty, creates more opportunities for innovations in the market for new ventures. Because of shifts in policies, new opportunities emerge (as do new threats) offering a fertile environment for new, agile ventures to spot and exploit new market opportunities. What this implies is that for every level of unique, non-mimetic knowledge utilization, the external knowledge that is obtained under uncertain environmental conditions can be recombined with internal knowledge and applied to a 
broader set of product innovations targeted at a richer set of market opportunities. The policy uncertainty also prods the venture to engage in more extensive boundary spanning activities of information transmission, filtering, summarization, interpretation that will enable integration and recombination of unique, non-mimetic knowledge and subsequently the conversion into new products (Aldrich and Herker, 1977; Rosenkopf and Nerkar, 2001).

It is important to recognize the contextual differences between the current study and prior literature that focused exclusively on developed economies such as the Laursen and Salter (2006) study. The novel products and services introduced in the UK market in the Laursen and Salter study are likely more knowledge-intensive and innovative and consequently require inputs from a broader range of diverse and dispersed external knowledge sources that populate the UK national innovation system. In a developing country context where knowledge is much scarcer and more concentrated, the main result emerging from our empirical analysis is that entrepreneurs should strike a balance between utilizing very unique, non-mimetic knowledge and using more familiar knowledge commonly used by peer firms to create new products. In other words, they should blend knowledge obtained through local search with knowledge obtained through distant search, i.e. utilize external knowledge that is moderately unique and that is also occasionally tapped by other firms. From a theoretical perspective, such actions would stimulate innovative performance (KBV) by increasing internal knowledge diversity through the acquisition, recombination and integration of external, relatively novel knowledge to create new products, while at the same time doing this in a legitimate manner that is consistent with institutional norms and prescriptions (institutional theory) and consistent with the limits of distant knowledge integration (KBV).

\section{Managerial Implications}


Two managerial implications for entrepreneurs are clear based on our empirical results. First, entrepreneurs can boost innovative performance by implementing strategic product planning when incorporating highly unique, non-mimetic knowledge in their products. In addition, by doing strategic product planning they increase the social legitimacy of their activities and enhance product acceptance. No strategic product planning is needed when entrepreneurs develop imitative 'me-too' type of products. Second, in environments with high levels of policy uncertainty, entrepreneurs need to engage in boundary spanning activities like externally searching for, utilizing, and recombining unique, non-mimetic knowledge to counter the effects of uncertainty and to swiftly exploit emerging opportunities.

\section{Limitations and Future Research}

This study has some limitations that open the door for future research. First, the sample restricts the identification of unique, non-mimetic knowledge originating from only three knowledge sources. Future studies should consider more than three sources of knowledge. That said, there are theoretical and empirical reasons why three knowledge sources may be sufficient since new ventures have difficulty developing external linkages with other important stakeholders (Fernhaber and Li, 2010; Stinchcombe, 1965). Second, the study is static in nature and therefore cannot make causality claims and account for dynamic effects. With longitudinal data, it would be valuable to examine our research questions in a dynamic context, and better control for unobserved firm-level heterogeneities. Especially, the longitudinal data will allow us to distinguish between the use of non-mimetic knowledge and the benefit from using the nonmimetic knowledge. Third, this study relies on the boundary spanning argument for Hypothesis 3 , yet it does not have actual data on the boundary spanning activities and only assume the policy uncertainty will give rise to boundary spanning activities. Fourth, the data only provides 
company-level data from developing countries. Manufacturing sectors in developed countries are underrepresented in the survey. In the future, the comparison between developing and developed countries can provide more insight in how new ventures manage their innovation processes.

\section{Conclusions}

By integrating the KBV and institutional theory and based on a large sample of new ventures across a range of developing countries, this study reveals that there is a curvilinear relationship between the utilization of unique, non-mimetic knowledge and innovative performance. The findings also suggest that strategic product planning helps in converting very unique, nonmimetic knowledge into new products. In addition, the empirical findings in this study suggest that policy uncertainty is also helpful, i.e. positively moderates the process of converting unique, non-mimetic knowledge into new products. This study hopes to provide a richer insight into the innovation processes of new ventures in developing countries, opening up an entire research area that can be explored in future studies. 


\section{REFERENCES}

Ahuja, G. and C. M. Lampert. 2001. Entrepreneurship in the large corporation: A longitudinal study of how established firms create breakthrough inventions. Strategic Management Journal 22(6-7): 521-543.

Aldrich, H. and D. Herker. 1977. Boundary spanning roles and organizational structure. Academy of Management Review 2: 217-230.

Armstrong, J. S. 1982. The value of formal planning for strategic decisions: Review of empirical research. Strategic Management Journal 3(3): 197-211.

Artz, K. W., P. M. Norman, D. E. Hatfield, and L. B. Cardinal. 2010. A longitudinal study of the impact of R\&D, patents, and product innovation on firm performance. Journal of Product Innovation Management 27(5): 725-740.

Audia, P. G. and J. A. Goncalo. 2007. Past success and creativity over time: A study of inventors in the hard disk drive industry. Management Science 53(1): 1-15.

Barbosa, N. and A. P. Faria. 2011. Innovation across Europe: How important are institutional differences? Research Policy 40: 1157-1169.

Baum, J., T. Calabrese, and B. S. Silverman. 2000. Don't go it alone: Alliance network composition and startups' performance in Canadian biotechnology. Strategic Management Journal 21: 267-294.

Beck, T., A. Demirguc-Kunt, and V. Maksimovic. 2008. Financing patterns around the world: Are small firms different? Journal of Financial Economics 89(3): 467-487.

Boardman, C. 2009. Government centrality to university-industry interactions: University research centers and the industry involvement of academic researchers. Research Policy 38: 1505-1516.

Bowen, H. and D. De Clercq. 2008. Institutional context and the allocation of entrepreneurial effort. Journal of International Business Studies 39: 747-767.

Bozeman, B. and M. Gaughan. 2007. Impacts of grants and contracts on academic researchers' interactions with industry. Research Policy 36: 694-707.

Calantone, R., R. Garcia, and C. Dröge. 2003. The effects of environmental turbulence on new product development strategy planning. Journal of Product Innovation Management 20(2): 90103.

Carpenter, M. A., T. G. Pollock, and M. M. Leary. 2003. Testing a model of reasoned risktaking: Governance, the experience of principals and agents, and global strategy in hightechnology IPO firms. Strategic Management Journal 24(9): 803-820.

Cassiman, B. and R. Veugelers. 2006. In search of complementarity in innovation strategy: Internal R\&D and external knowledge acquisition. Management Science 52(1): 68-82.

Chen, W. R. 2008. Determinants of firms' backward- and forward-looking R\&D search behavior. Organization Science 19(4): 609-622.

Cheng, C. and E. Huizingh. 2014. When is open innovation beneficial? The role of strategic orientation. Journal of Product Innovation Management 31(6): 1235-1253.

Chesbrough, H. W. 2003. Open innovation: The new imperative for creating and profiting from technology. Boston, MA: Harvard Business School Press.

Chwolka, A. and M. G. Raith. 2012. The value of business planning before start-up - A decisiontheoretical perspective. Journal of Business Venturing 27(3): 385-399.

Cohen, W. and D. Levinthal. 1990. Absorptive capacity: A new perspective on learning and innovation. Administrative Science Quarterly 35(1): 128-152. 
Conner, K. R. and C. K. Prahalad. 1996. A resource-based theory of the firm: Knowledge versus opportunism. Organization Science 7(5), 477-501.

Delmar, F. and S. Shane. 2003. Does business planning facilitate the development of new ventures? Strategic Management Journal 24(12): 1165-1185.

DiMaggio, P. J. and W. W. Powell. 1983. The Iron Cage Revisited: Institutional Isomorphism and Collective Rationality in Organizational Fields. American Sociological Review 48(2): 147-160.

Fagerberg, J. and M. Srholec. 2008. National innovation systems, capabilities and economic development. Research Policy 37(9): 1417-1435.

Fernhaber, S. and D. Li. 2010. The impact of interorganizational imitation on new venture international entry and performance. Entrepreneurship Theory and Practice 34(1): 1-30. Fleming, L. 2001. Recombinant uncertainty in technological search. Management Science 47: 117-132.

Fleming, L. and O. Sorenson. 2004. Science as a map in technological search. Strategic Management Journal 25: 909-928.

Freel, M. 2005. Perceived Environmental Uncertainty and Innovation in small firms. Small Business Economics 25: 49-64.

Freeman, J., G. R. Carroll, and M. T. Hannan. 1983. The liability of newness: Age dependence in organizational death rates. American Sociological Review 48(5): 692-710.

Freeman, C. and L. Soete. 1997. The Economics of Industrial Innovation. Psychology Press.

Grant, R. M. 1991. The resource-based theory of competitive advantage. California Management Review 33(3): 114-135.

Grant, R. M. 1996. Toward a knowledge-based theory of the firm. Strategic Management Journal 17: 109-122.

Hargadon, A. and R. I. Sutton. 1997. Technology brokering and innovation in product development firm. Administrative Science Quarterly 42(4): 716-749.

Hoetker, G. 2007. The use of logit and probit models in strategic management research: Critical issues. Strategic Management Journal 28: 331-343.

Hoffmann, J. P. 2004. Generalized Linear Models. Pearson Education.

Intarakumnerd, P., P. Chairatana, and T. Tangchipiboon. 2002. National innovation system in less successful developing countries: The case of Thailand. Research Policy 31: 1445-1457.

Jansen, J., F. Van Den Bosch, and H. Volberda. 2006. Exploratory innovation, exploitative innovation, and performance: Effects of organizational antecedents and environmental moderators. Management Science 52(11), 1661-1674.

Jeppesen, L. B. and K. R. Lakhani. 2010. Marginality and problem-solving effectiveness in broadcast search. Organization Science 21(5): 1016-1033.

Jones, G. K., A. Lanctot Jr, and H. J. Teegen. 2001. Determinants and performance impacts of external technology acquisition. Journal of Business Venturing 16(3): 255-283.

Kanter, R. M. 1988. Three tiers for innovation research. Communication Research 15(5): 509523.

Kapoor, R. and R. Adner. 2012. What firms make vs. what they know: how firms' production and knowledge boundaries affect competitive advantage in the face of technological change. Organization Science 23(5), 1227-1248.

Karim, S. 2009. Business unit reorganization and innovation in new product markets. Management Science 55(7), 1237-1254.

Katila, R. 2002. New product search over time: Past ideas in their prime? Academy of Management Journal 45(5): 995-1010. 
Katila, R. and G. Ahuja. 2002. Something old, something new: A longitudinal study of search behavior and new product introduction. Academy of Management Journal 45(6): 1183-1194. Khavul, S. and C. D. Bruton. 2013. Harnessing innovation for change: Sustainability and poverty in developing countries. Journal of Management Studies 50(2): 285-306.

Kogut, B. and U. Zander. 1992. Knowledge of the firm, combinative capabilities, and the replication of technology. Organization Science 3(3): 383-397.

Kostova, T. and K. Roth. 2002. Adoption of an organizational practice by subsidiaries of multinational corporations: Institutional and relational effects. Academy of Management Journal 45(1): 215-233.

Laursen, K. 2012. Keep searching and you'll find: What do we know about variety creation through firms' search activities for innovation? Industrial and Corporate Change 21(5): 11811220.

Laursen, K. and A. Salter. 2006. Open for innovation: The role of openness in explaining innovation performance among UK manufacturing firms. Strategic Management Journal 27: 131-50.

Lee, S., G. Park, B. Yoon, and J. Park. 2010. Open innovation in SMEs - An intermediated networked model. Research Policy 39(2): 290-300.

Leiponen, A. and C. E. Helfat. 2010. Innovation objectives, knowledge sources, and the benefits of breadth. Strategic Management Journal 31(2): 224-236.

Levinthal, D. A. and J. G. March. 1993. The myopia of learning. Strategic Management Journal 14(S2): 95-112.

Li, Y. and T. Chi. 2013. Venture capitalists' decision to withdraw: The role of portfolio configuration from a real options lens. Strategic Management Journal 34(11): 1351-1366. Li, Q., P. Maggitti, K. G. Smith, P. E. Tesluk, and R. Katila. 2013. Top management attention to innovation: The role of search selection and intensity in new product introductions. Academy of Management Journal 56: 893-916.

Libaers, D. and T. Wang. 2012. Foreign-born academic scientists: Entrepreneurial academics or academic entrepreneurs? R\&D Management 42(3): 254-272.

Long, J. S. 1997. Regression Models for Categorical and Limited Dependent Variables. Sage. Lundvall, B. Å. 2010. National Systems of Innovation: Toward a Theory of Innovation and Interactive Learning (Vol. 2). Anthem Press.

Macher, J. T. and C. Boerner. 2012. Technological development at the boundaries of the firm: a knowledge-based examination in drug development. Strategic Management Journal 33(9): 10161036.

Marcus, A. A. 1981. Policy uncertainty and technological innovation. Academy of Management Review 6(3): 443-448.

Martin, K., J. Cullen, J. Johnson, and P. Parboteeah. 2007. Deciding to bribe: A cross-level analysis of firm and home country influences on bribery activity. Academy of Management Journal 50(6): 1401-1422.

Miles, R. H. 1980. Macro organizational behavior. Santa Monica, CA: Goodyear.

Miller, C. C. and L. B. Cardinal. 1994. Strategic planning and firm performance: A synthesis of more than two decades of research. Academy of Management Journal 37(6): 1649-1665.

Moorman, C. and A. S. Miner. 1998. The convergence of planning and execution: Improvisation in new product development. Journal of Marketing 62(July): 1-20.

Nickerson, J. A. and T. R. Zenger. 2004. A knowledge-based theory of the firm - The problemsolving perspective. Organization Science 15(6), 617-632. 
Nooteboom, B. 2000. Learning and Innovation in Organizations and Economies. Oxford University Press.

Nooteboom, B., W. Van Haverbeke, G. Duysters, V. Gilsing, and A. Van den Oord. 2007. Optimal cognitive distance and absorptive capacity. Research Policy 36(7): 1016-1034.

North, D. C. 1990. Institutions, Institutional Change and Economic Performance. Cambridge University Press.

Oliver, C. 1991. Strategic responses to institutional processes. Academy of Management Review 16(1): 145-179.

Padilla-Perez, R. and Y. Gaudin. 2014. Science, technology and innovation policies in small and developing economies: the case of Central America. Research Policy 43: 749-759.

Phelps, C. C. 2010. A longitudinal study of the influence of alliance network structure and composition on firm exploratory innovation. Academy of Management Journal, 53(4): 890-913. Phene, A., K. Fladmoe-Lindquist, and L. Marsh. 2006. Breakthrough innovations in the US biotechnology industry: The effects of technological space and geographic origin. Strategic Management Journal 27(4): 369-388.

Rodrik, D. 1991. Policy uncertainty and private investment in developing countries. Journal of Development Economics, 36(2): 229-242.

Romanelli, E. 1989. Environments and strategies of organization start-up: Effects on early survival. Administrative Science Quarterly 34(3): 369-387.

Rosenkopf, L. and A. Nerkar. 2001. Beyond local search: boundary-spanning, exploration, and impact in the optical disk industry. Strategic Management Journal 22(4): 287-3

Salge, T., T. Farchi, M. Barrett, and S. Dopson. 2013. When does search openness really matter? A contingency study of health-care innovation projects. Journal of Product Innovation Management 30(4): 659-676.

Smith, K. G., C. J. Collins, and K. D. Clark. 2005. Existing knowledge, knowledge creation capability, and the rate of new product introduction in high-technology firms. Academy of Management Journal 48(2): 346-357.

Song, M., S. Im, H. Bij, and L. Song. 2011. Does strategic planning enhance or impede innovation and firm performance. Journal of Product Innovation Management 28: 503-520. Stinchcombe, A. L. 1965. Social structure and organizations, in March, J. G. (Eds.), Handbook of Organizations. Rand McNally.

Tolbert, P. S. and L. G. Zucker. 1983. Institutional sources of change in the formal structure of organizations: The diffusion of civil service reform, 1880-1935. Administrative Science Quarterly 28(1): 22-39.

Tranekjar, T. and M. P. Knudsen. 2012. The (unknown) providers to other firms' new product development: What's in it of them? Journal of Product Innovation Management 29(6): 986-999. Vasudeva, G. and J. Anand. 2011. Unpacking absorptive capacity: A study of knowledge utilization from alliance portfolios. Academy of Management Journal 54(3): 611-623.

West, J. and M. Bogers. 2014. Leveraging external sources of innovation: A review of research on open innovation. Journal of Product Innovation Management 31(4), 814-831.

Westphal, J. D., R. Gulati, and S. M. Shortell. 1997. Customization or conformity? An institutional and network perspective on the content and consequences of TQM adoption. Administrative Science Quarterly 42(2): 366-394.

Zahra, S. A. and G. George. 2002. Absorptive capacity: A review, reconceptualization, and extension. Academy of Management Review 27(2): 185-203. 
Zelner, B. A. 2009. Using simulation to interpret results from logit, probit, and other nonlinear models. Strategic Management Journal 30: 1335-1348. 
TABLE 1

\section{Sample Description of Enterprise Survey}

Part A: Countries in the Enterprise Survey

\begin{tabular}{|c|c|c|c|c|c|c|c|}
\hline Country & Country & Country & Country & Country & Country & Country & Country \\
\hline Albania & Chile & $\begin{array}{l}\text { Republic of } \\
\text { Macedonia }\end{array}$ & Kazakhstan & Mexico & Romania & Thailand & Burundi \\
\hline Algeria & China & Georgia & Kenya & Moldova & Russia & Turkey & $\begin{array}{l}\text { Cameroon } \\
\text { cape }\end{array}$ \\
\hline Argentina & Colombia & Germany & Kyrgyzstan & Mongolia & Senegal & Uganda & Verde \\
\hline Armenia & Costa Rica & Greece & Laos & Montenegro & Serbia & Ukraine & DRC \\
\hline Azerbaijan & Croatia & Guatemala & Latvia & Nicaragua & Slovakia & Uruguay & Gambia \\
\hline Bangladesh & $\begin{array}{l}\text { Czech } \\
\text { Dominican }\end{array}$ & Guyana & Lebanon & Oman & $\begin{array}{l}\text { Slovenia } \\
\text { South }\end{array}$ & Uzbekistan & Guinea \\
\hline Belarus & Republic & Honduras & Lesotho & Pakistan & $\begin{array}{l}\text { Africa } \\
\text { South }\end{array}$ & Venezuela & Mauritania \\
\hline Benin & Ecuador & Hungary & Lithuania & Panama & Korea & $\begin{array}{l}\text { Vietnam } \\
\text { West }\end{array}$ & Namibia \\
\hline $\mathrm{BiH}$ & Egypt & India & Madagascar & Paraguay & Spain & Bank_Gaza & Niger \\
\hline Bolivia & El Salvador & Indonesia & Malawi & Peru & Sri Lanka & Zambia & Rwanda \\
\hline Brazil & Eritrea & Ireland & Malaysia & Philippines & Syria & Angola & Swaziland \\
\hline Bulgaria & Estonia & Jamaica & Mali & Poland & Tajikistan & $\begin{array}{l}\text { Botswana } \\
\text { Burkina }\end{array}$ & Tanzania \\
\hline Cambodia & Ethiopia & Jordan & Mauritius & Portugal & Tanzania & Faso & Uganda \\
\hline
\end{tabular}

Part B: Industries in the Enterprise Survey

Textiles, leather, garments:
$>$ Textiles
$>$ Leather
$>$ Garments

Food and beverage:

$>$ Food

$>$ Beverages

Machinery, electronics, chemical and other materials:

$>$ Metals and machinery

$>$ Electronics

$>$ Chemicals and pharmaceutics

$>$ Wood and furniture

$>$ Non-metallic and plastic materials

$>$ Paper

Other manufacturing:

$>$ auto and auto components

$>$ Other transport equipment 
TABLE 2

Descriptive Statistics

\begin{tabular}{|c|c|c|c|c|c|c|c|c|c|c|c|c|c|c|c|c|c|}
\hline Correlation matrix & 1 & 2 & 3 & 4 & 5 & 6 & 7 & 8 & 9 & 10 & 11 & 12 & 13 & 14 & 15 & 16 & 17 \\
\hline 1.Number of new products & 1.00 & & & & & & & & & & & & & & & & \\
\hline 2.Uni. knowledge & 0.14 & 1.00 & & & & & & & & & & & & & & & \\
\hline 3.Str. planning (natural log) & 0.14 & 0.29 & 1.00 & & & & & & & & & & & & & & \\
\hline 4.Pol. uncertainty & 0.04 & 0.23 & 0.17 & 1.00 & & & & & & & & & & & & & \\
\hline 5.Firm age & -0.02 & -0.03 & -0.12 & -0.03 & 1.00 & & & & & & & & & & & & \\
\hline 6.Firm size (natural log) & -0.02 & 0.18 & -0.02 & -0.07 & 0.14 & 1.00 & & & & & & & & & & & \\
\hline $\begin{array}{l}\text { 7.TMT education level } \\
\text { 8.TMT work experience }\end{array}$ & 0.06 & 0.13 & 0.12 & 0.01 & 0.01 & 0.28 & 1.00 & & & & & & & & & & \\
\hline (natural $\log$ ) & 0.05 & 0.13 & 0.16 & 0.02 & -0.11 & 0.07 & -0.07 & 1.00 & & & & & & & & & \\
\hline 9. Foreign investment & -0.03 & 0.00 & -0.02 & -0.11 & 0.07 & 0.37 & 0.22 & 0.03 & 1.00 & & & & & & & & \\
\hline 10.R\&D investment & 0.11 & 0.12 & 0.20 & 0.05 & 0.00 & 0.07 & 0.10 & 0.11 & 0.05 & 1.00 & & & & & & & \\
\hline 11.Public firm & -0.01 & -0.04 & 0.04 & -0.06 & -0.01 & -0.02 & 0.05 & 0.01 & 0.03 & 0.07 & 1.00 & & & & & & \\
\hline $\begin{array}{l}\text { 12.Textiles, leather, and } \\
\text { garments }\end{array}$ & -0.11 & 0.10 & 0.03 & 0.14 & -0.01 & -0.03 & -0.11 & 0.00 & -0.14 & 0.00 & -0.01 & 1.00 & & & & & \\
\hline 13.Food and beverages & -0.01 & -0.05 & -0.03 & -0.03 & -0.03 & 0.02 & 0.04 & -0.07 & -0.13 & -0.04 & 0.04 & -0.28 & 1.00 & & & & \\
\hline materials & 0.08 & -0.08 & 0.00 & -0.08 & 0.01 & -0.03 & 0.04 & 0.03 & 0.13 & 0.03 & 0.00 & -0.67 & -0.38 & 1.00 & & & \\
\hline 15.Other industries & 0.06 & 0.05 & -0.02 & -0.07 & 0.05 & 0.08 & 0.07 & 0.05 & 0.18 & -0.02 & -0.05 & -0.18 & -0.10 & -0.24 & 1.00 & & \\
\hline 16.Operational slack & 0.02 & 0.07 & -0.02 & -0.04 & 0.06 & 0.21 & 0.03 & -0.02 & 0.06 & -0.01 & -0.01 & 0.04 & -0.06 & -0.02 & 0.04 & 1.00 & \\
\hline 17.Process innovation & 0.17 & 0.27 & 0.13 & 0.15 & 0.03 & 0.13 & 0.06 & 0.04 & 0.00 & 0.11 & 0.00 & 0.01 & 0.00 & -0.03 & 0.04 & 0.12 & 1.00 \\
\hline Mean & 1.69 & 1.53 & 0.93 & 2.04 & 6.29 & 3.85 & 4.06 & 1.63 & 0.17 & 0.48 & 0.05 & 0.33 & 0.14 & 0.47 & 0.06 & 74.60 & 0.51 \\
\hline Std Dev & 3.05 & 0.79 & 0.98 & 1.48 & 2.56 & 1.38 & 1.53 & 1.27 & 0.37 & 0.50 & 0.23 & 0.47 & 0.34 & 0.50 & 0.24 & 18.88 & 0.50 \\
\hline Minimum & 0.00 & 0.00 & 0.00 & 0.00 & 0.00 & 0.00 & 1.00 & 0.00 & 0.00 & 0.00 & 0.00 & 0.00 & 0.00 & 0.00 & 0.00 & 1.00 & 0 \\
\hline Maximum & 15.00 & 2.71 & 4.80 & 4.00 & 10.00 & 8.68 & 6.00 & 3.93 & 1.00 & 1.00 & 1.00 & 1.00 & 1.00 & 1.00 & 1.00 & 106.00 & 1 \\
\hline
\end{tabular}

Note: The correlation whose absolute value is above 0.05 is significant at $5 \%$ level. The sample size for variable 1-16 is 1583 and the sample size for variable 17 (process innovation) is 1507. 
TABLE 3

\section{Negative Binomial Regression Model Predicting Innovative Performance}

\begin{tabular}{|c|c|c|c|c|c|c|c|c|c|c|}
\hline \multirow{2}{*}{$\begin{array}{l}\text { DV: Number of new } \\
\text { products } \\
\text { Parameter }\end{array}$} & \multicolumn{2}{|c|}{ Model 1} & \multicolumn{2}{|c|}{ Model 2} & \multicolumn{2}{|c|}{ Model 3} & \multicolumn{2}{|c|}{ Model 4} & \multicolumn{2}{|c|}{ Model 5} \\
\hline & $\beta$ & SE & $\beta$ & SE & $\beta$ & SE & $\beta$ & SE & $\beta$ & SE \\
\hline Intercept & -0.37 & 0.44 & -0.09 & 0.44 & -0.11 & 0.44 & -0.23 & 0.44 & -0.23 & 0.44 \\
\hline Firm age & 0.02 & 0.02 & 0.01 & 0.02 & 0.01 & 0.02 & 0.02 & 0.02 & 0.02 & 0.02 \\
\hline Firm size (natural log) & 0.05 & 0.05 & 0.04 & 0.05 & 0.03 & 0.05 & 0.04 & 0.05 & 0.03 & 0.05 \\
\hline TMT education level & 0.02 & 0.04 & 0.01 & 0.04 & 0.01 & 0.04 & 0.01 & 0.04 & 0.01 & 0.04 \\
\hline TMT work experience & 0.03 & 0.04 & 0.03 & 0.04 & 0.03 & 0.04 & 0.03 & 0.04 & 0.03 & 0.04 \\
\hline Foreign investment & -0.07 & 0.16 & -0.10 & 0.16 & -0.10 & 0.16 & -0.09 & 0.15 & -0.09 & 0.15 \\
\hline R\&D investment & $0.50 * *$ & 0.12 & $0.50 * *$ & 0.12 & $0.51 * *$ & 0.12 & $0.48 * *$ & 0.12 & $0.49 * *$ & 0.12 \\
\hline \multirow{2}{*}{$\begin{array}{l}\text { Public firm } \\
\text { Textiles, leather, and } \\
\text { garments }\end{array}$} & 0.13 & 0.26 & 0.09 & 0.26 & 0.09 & 0.26 & 0.10 & 0.26 & 0.10 & 0.26 \\
\hline & $-0.99 * *$ & 0.24 & $-0.88 * *$ & 0.24 & $-0.88 * *$ & 0.24 & $-0.85^{* *}$ & 0.24 & $-0.85^{* *}$ & 0.24 \\
\hline \multirow{2}{*}{$\begin{array}{l}\text { Food and beverages } \\
\text { Machinery, electronics, } \\
\text { chemicals, and other } \\
\text { materials }\end{array}$} & $-0.68 *$ & 0.26 & $-0.60 *$ & 0.26 & $-0.57^{*}$ & 0.26 & $-0.56^{*}$ & 0.26 & $-0.54 *$ & 0.26 \\
\hline & -0.36 & 0.22 & -0.28 & 0.22 & -0.29 & 0.22 & -0.27 & 0.22 & -0.28 & 0.22 \\
\hline Operational slack & 0.00 & 0.00 & 0.00 & 0.00 & 0.00 & 0.00 & 0.00 & 0.00 & 0.00 & 0.00 \\
\hline Str. planning & 0.06 & 0.07 & 0.06 & 0.07 & -0.07 & 0.11 & 0.06 & 0.07 & -0.04 & 0.11 \\
\hline Pol. uncertainty & -0.01 & 0.06 & 0.00 & 0.06 & 0.00 & 0.06 & $-0.15+$ & 0.08 & $-0.14+$ & 0.08 \\
\hline Uni. Knowledge (H1) & & & 0.11 & 0.10 & 0.06 & 0.11 & 0.05 & 0.11 & 0.02 & 0.11 \\
\hline Uni. knowledge $^{2}(\mathrm{H} 1)$ & & & $-0.20 * *$ & 0.07 & $-0.23^{* *}$ & 0.07 & $-0.23 * *$ & 0.07 & $-0.25^{* *}$ & 0.07 \\
\hline $\begin{array}{l}\text { Str. planning*Uni. } \\
\text { knowledge (H2) } \\
\text { Str. planning*Uni. }\end{array}$ & & & & & $0.13+$ & 0.07 & & & $0.12+$ & 0.07 \\
\hline \multicolumn{10}{|l|}{ Pol. uncertainty*Uni. } & 0.07 \\
\hline $\begin{array}{l}\text { Knowledge (H3) } \\
\text { Pol. uncertainty* Uni. }\end{array}$ & & & & & & & 0.04 & 0.07 & 0.03 & 0.07 \\
\hline $\begin{array}{l}\text { knowledge }^{2}(\mathrm{H} 3) \\
\text { Country dummy fixed }\end{array}$ & & & & & & & $0.16^{* *}$ & 0.06 & $0.15^{*}$ & 0.06 \\
\hline effect & \multicolumn{2}{|c|}{ Included } & \multicolumn{2}{|c|}{ Included } & \multicolumn{2}{|c|}{ Included } & \multicolumn{2}{|c|}{ Included } & \multicolumn{2}{|c|}{ Included } \\
\hline Dispersion & 3.13 & 0.19 & 3.02 & 0.19 & 3.01 & 0.19 & 2.99 & 0.19 & 2.98 & 0.19 \\
\hline Log Likelihood & \multicolumn{2}{|c|}{515.44} & \multicolumn{2}{|c|}{527.82} & \multicolumn{2}{|c|}{529.55} & \multicolumn{2}{|c|}{532.13} & \multicolumn{2}{|c|}{533.42} \\
\hline $\mathrm{N}$ of firms & \multicolumn{2}{|c|}{1583} & \multicolumn{2}{|c|}{1583} & \multicolumn{2}{|c|}{1583} & \multicolumn{2}{|c|}{1583} & \multicolumn{2}{|c|}{1583} \\
\hline
\end{tabular}

Note: $* *: p<0.01, *: p<0.05,+: p<0.10 ;$ predictors and moderators are standardized. 
TABLE 4

\section{Robustness Test}

\begin{tabular}{|c|c|c|c|c|c|c|c|c|c|c|}
\hline \multirow[b]{2}{*}{ Parameter } & \multicolumn{2}{|c|}{$\begin{array}{c}\text { Model 6 } \\
\text { Machinery, } \\
\text { electronics, chemicals } \\
\end{array}$} & \multicolumn{2}{|c|}{$\begin{array}{c}\text { Model } 7 \\
\text { High-income countries } \\
(\text { GNI }>\$ 1000) \\
\end{array}$} & \multicolumn{2}{|c|}{$\begin{array}{c}\text { Model } 8 \\
\text { Brazil \& South } \\
\text { Africa } \\
\end{array}$} & \multicolumn{2}{|c|}{$\begin{array}{c}\text { Model } 9 \\
\text { DV = Process } \\
\text { innovation }\end{array}$} & \multicolumn{2}{|c|}{$\begin{array}{c}\text { Model 10 } \\
\text { Developed } \\
\text { countries added } \\
\end{array}$} \\
\hline & $\beta$ & SE & $\beta$ & SE & $\beta$ & SE & $\beta$ & $\mathrm{SE}$ & $\beta$ & SE \\
\hline Intercept & -0.54 & 0.55 & -0.20 & 0.49 & 0.45 & 0.66 & $-2.15 * *$ & 0.50 & 0.77 & 0.61 \\
\hline Firm age & 0.00 & 0.03 & 0.03 & 0.02 & 0.04 & 0.03 & $0.06^{*}$ & 0.02 & $0.05^{*}$ & 0.02 \\
\hline Firm size (natural log) & 0.04 & 0.07 & -0.01 & 0.05 & -0.03 & 0.08 & $0.26 * *$ & 0.06 & $0.28^{* *}$ & 0.05 \\
\hline TMT education level & 0.01 & 0.05 & 0.02 & 0.04 & 0.02 & 0.05 & 0.01 & 0.04 & & \\
\hline TMT work experience & 0.03 & 0.06 & 0.05 & 0.04 & $0.09+$ & 0.05 & 0.02 & 0.05 & & \\
\hline Foreign investment & -0.10 & 0.18 & -0.08 & 0.17 & -0.01 & 0.28 & -0.12 & 0.18 & -0.09 & 0.17 \\
\hline R\&D investment & $0.68 * *$ & 0.16 & $0.47 * *$ & 0.12 & $0.38^{* *}$ & 0.14 & $0.53 * *$ & 0.13 & $0.47^{* *}$ & 0.12 \\
\hline \multirow{2}{*}{$\begin{array}{l}\text { Public firm } \\
\text { Textiles, leather, and } \\
\text { garments }\end{array}$} & 0.10 & 0.34 & 0.21 & 0.30 & 0.30 & 0.53 & 0.41 & 0.30 & 0.24 & 0.28 \\
\hline & 0.00 & 0.00 & $-1.04 * *$ & 0.25 & -0.26 & 0.30 & -0.29 & 0.27 & -0.28 & 0.25 \\
\hline \multirow{2}{*}{$\begin{array}{l}\text { Food and beverages } \\
\text { Machinery, electronics, } \\
\text { chemicals, and other } \\
\text { materials }\end{array}$} & 0.00 & 0.00 & $-0.52+$ & 0.27 & 0.05 & 0.35 & -0.14 & 0.30 & -0.21 & 0.27 \\
\hline & 0.00 & 0.00 & -0.36 & 0.22 & -0.11 & 0.29 & -0.40 & 0.25 & -0.38 & 0.24 \\
\hline Operational slack & 0.00 & 0.00 & 0.00 & 0.00 & 0.00 & 0.00 & $0.01 * *$ & 0.00 & $0.01 * *$ & 0.00 \\
\hline Str. planning & -0.19 & 0.14 & -0.04 & 0.13 & 0.06 & 0.17 & -0.08 & 0.12 & -0.11 & 0.11 \\
\hline Pol. uncertainty & -0.16 & 0.10 & -0.11 & 0.08 & -0.14 & 0.16 & 0.07 & 0.09 & 0.03 & 0.09 \\
\hline Uni. knowledge & -0.01 & 0.15 & 0.13 & 0.11 & $0.31^{*}$ & 0.14 & 0.18 & 0.12 & $0.77^{* *}$ & 0.10 \\
\hline \multirow{6}{*}{$\begin{array}{l}\text { Uni. Knowledge } \\
\text { Str. planning*Uni. } \\
\text { knowledge } \\
\text { Str. planning*Uni. } \\
\text { Knowledge } \\
\text { Pol. uncertainty*Uni. } \\
\text { knowledge } \\
\text { Pol. uncertainty*Uni. } \\
\text { Knowledge }^{2} \\
\text { Country dummy fixed } \\
\text { effect }\end{array}$} & $-0.31 * *$ & 0.10 & $-0.35^{* *}$ & 0.08 & $-0.42 * *$ & 0.14 & $-0.41 * *$ & 0.08 & $-0.69 * *$ & 0.11 \\
\hline & $0.26 * *$ & 0.10 & $0.18^{*}$ & 0.08 & 0.11 & 0.12 & 0.10 & 0.08 & -0.09 & 0.08 \\
\hline & $0.18^{*}$ & 0.09 & 0.01 & 0.08 & 0.00 & 0.12 & $0.12+$ & 0.07 & $0.23 * *$ & 0.09 \\
\hline & $0.20^{*}$ & 0.10 & 0.07 & 0.08 & -0.13 & 0.12 & 0.09 & 0.08 & -0.01 & 0.08 \\
\hline & $0.30 * *$ & 0.08 & 0.08 & 0.07 & $0.26^{*}$ & 0.13 & 0.11 & 0.07 & $0.15+$ & 0.09 \\
\hline & \multicolumn{2}{|c|}{ Included } & \multicolumn{2}{|c|}{ Included } & \multicolumn{2}{|c|}{ Included } & \multirow{2}{*}{\multicolumn{2}{|c|}{ Included }} & \multirow{2}{*}{\multicolumn{2}{|c|}{ Included }} \\
\hline Dispersion & 2.35 & 0.21 & 2.74 & 0.19 & 1.96 & 0.18 & & & & \\
\hline $\begin{array}{l}\text { Log Likelihood } \\
\mathrm{N} \text { of firms }\end{array}$ & \multicolumn{2}{|c|}{365.30} & \multicolumn{2}{|c|}{519.08} & \multicolumn{2}{|c|}{401.08} & \multicolumn{2}{|c|}{-878.54} & \multicolumn{2}{|c|}{$\begin{array}{c}-1049.68 \\
1799\end{array}$} \\
\hline
\end{tabular}

Note: $* *: p<0.01, *: p<0.05,+: p<0.10$; predictors and moderators are standardized. GNI = Gross National Income. 
FIGURE 1

Moderating Effect of Strategic Product Planning

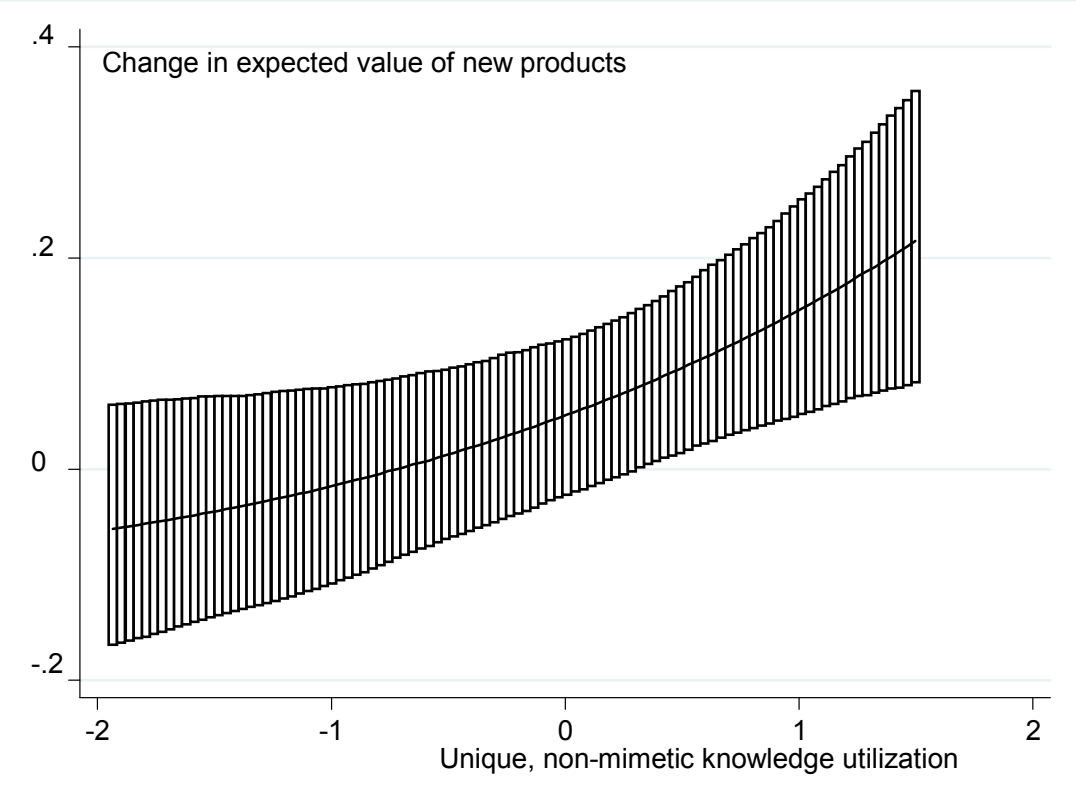

Note: the $\mathrm{x}$-axis variable $=$ standardized unique, non-mimetic knowledge. The shaded region includes the $95 \%$ confidence interval.

FIGURE 2

\section{Moderating Effect of Policy Uncertainty}

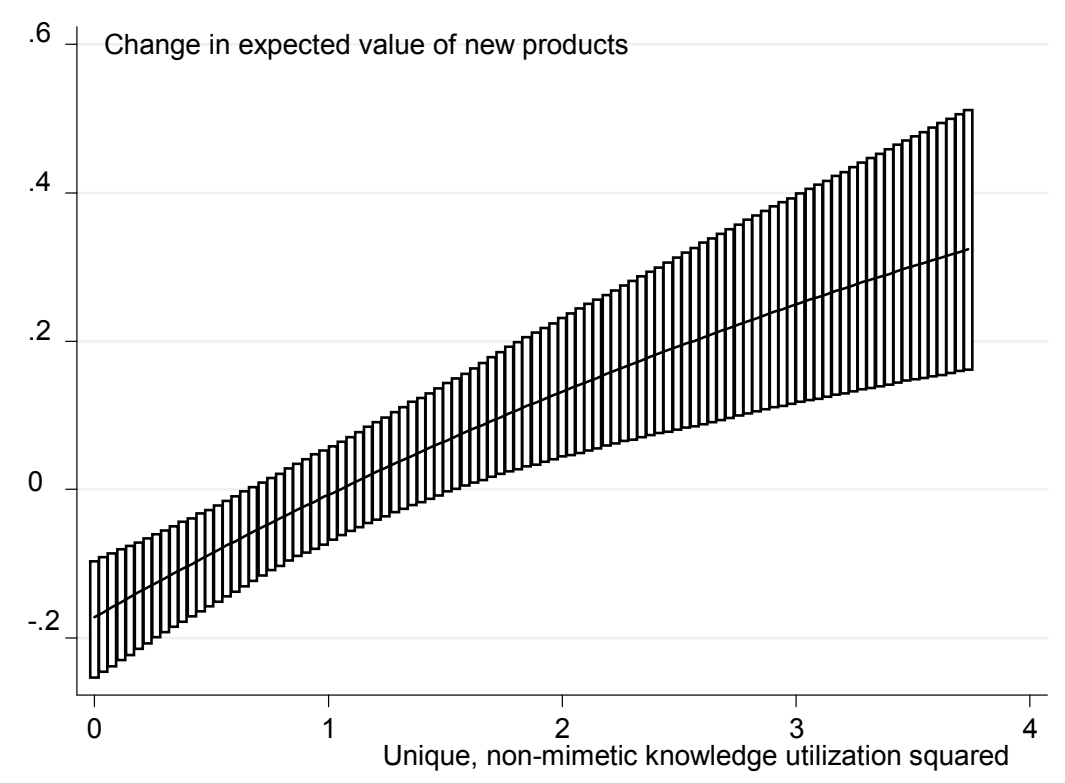

Note: the $\mathrm{x}$-axis variable $=(\text { standardized unique, non-mimetic knowledge })^{2}$. The shaded region includes the $95 \%$ confidence interval. 